\title{
The association between parity and spontaneous preterm birth: a population based study
}

Bouchra Koullali ${ }^{1 *}$, Maud D. van Zijl', Brenda M. Kazemier', Martijn A. Oudijk', Ben W. J. Mol², Eva Pajkrt ${ }^{1}$ and Anita C. J. Ravelli ${ }^{1,3}$

\begin{abstract}
Background: Preterm birth is the leading cause of perinatal mortality and neonatal morbidity worldwide. Many factors have been associated with preterm birth, including parity. The aim of the present study was to investigate associations between parity and risk of spontaneous preterm birth.

Methods: We conducted a retrospective study including live singleton births ( $\geq 22$ weeks) of women with a first, second, third, fourth or fifth pregnancy in The Netherlands from 2010 through 2014. Our primary outcome was risk of spontaneous preterm birth $<37$ weeks. Secondary outcomes were spontaneous preterm birth $<32$ and $<28$ weeks.

Results: We studied 802,119 pregnancies, including 30,237 pregnancies that ended spontaneously < 37 weeks. We identified an increased risk for spontaneous preterm birth < 37 weeks in nulliparous women (OR 1.95, 95\% Cl 1.892.00) and women in their fifth pregnancy (OR 1.26, 95\% Cl 1.13-1.41) compared to women in their second pregnancy. Similar results were seen for spontaneous preterm birth $<32$ and $<28$ weeks.

Conclusion: Our data show an independent association between nulliparity and spontaneous preterm birth $<37$, $<32$ and $<28$ weeks. Furthermore, we observed an increased risk for spontaneous preterm birth in women in their fifth pregnancy, with highest risk for preterm birth at early gestational age.
\end{abstract}

Keywords: Spontaneous preterm birth, Parity, Nulliparity, Risk factors

\section{Background}

Preterm birth, defined as birth before 37 weeks of gestation, is the leading cause of perinatal mortality and neonatal morbidity worldwide, mostly due to respiratory immaturity, intracranial hemorrhages and infections $[1$, 2]. Morbidity and mortality rates increase with decreasing gestational age [3]. Fifteen million children are born preterm worldwide each year, of which almost two and a

\footnotetext{
* Correspondence: b.koullali@amsterdamumc.nl

${ }^{1}$ Department of Obstetrics and Gynecology, Amsterdam UMC, University of Amsterdam, Meibergdreef 9, 1105, AZ, Amsterdam, The Netherlands Full list of author information is available at the end of the article
}

half million children are born before 32 weeks of gestation [4].

Preterm birth is considered a syndrome that can be initiated by multiple mechanisms such as intrauterine infection and inflammation, uteroplacental ischemia and hemorrhage, uterine overdistension, cervical insufficiency, hormonal disorders, and other immunologically mediated processes [5]. Defining maternal risk factors for preterm birth in epidemiological studies can provide important insights into mechanisms that lead to preterm birth and help to identify women at risk. This can lead to the introduction of risk-specific treatment and counseling [6]. 
There are many maternal characteristics that have been associated with preterm birth, including demographic characteristics (i.e. low socioeconomic status), low or high body-mass index (BMI), smoking and a previous preterm birth [6, 7]. Parity is another factor associated with preterm birth, with the highest rates reported in nulliparous women and the lowest rates reported in second births [8]. Studies on the association between high parity and adverse pregnancy outcomes show conflicting results. A number of studies did report an association between high parity and adverse pregnancy outcomes $[9,10]$. In contrast, other studies state that, under satisfactory socioeconomic and health care conditions, high parity should not be considered as a risk factor for adverse pregnancy outcomes [11]. A systematic review from 2010 shows that grand multiparity and great grand multiparity were not associated with increased risk of preterm birth [12].

The principal aim of the present study was to investigate associations between parity and risk of spontaneous preterm birth, assessing first, second, third, fourth and fifth pregnancies, using a large population-based study.

\section{Methods}

\section{Dataset}

This study was based on data from the Netherlands Perinatal Registry (PERINED). This database is a population based registry that covers approximately $97 \%$ of all deliveries in The Netherlands and contains information on deliveries at $\geq 22$ weeks of gestation and birth weight of $\geq 500 \mathrm{~g}$. Furthermore, all admissions to the neonatology care unit are registered until 28 days after birth. The perinatal database is obtained by a validated linkage of 3 different registries: the midwifery registry (LVR1), the obstetrics registry (LVR2), and the neonatology registry (LNR) of hospital admissions of new-born infants [13, 14]. It is used primarily for an annual assessment of the quality indicators of obstetric care.

\section{Ethical approval}

The data in the perinatal registry are anonymous; therefore, ethical approval was not mandatory under Dutch law. The Netherlands Perinatal Registry gave their approval for the use of their data for this study (approval no. 17.34).

\section{Inclusion and exclusion criteria}

We studied singleton first, second, third, fourth and fifth pregnancies (P0 through $\mathrm{P} 4$ ) resulting in delivery between 22 and 43 weeks of gestation in the 5-year period from 2010 through 2014. We excluded multiple pregnancies and pregnancies that were complicated by congenital abnormalities or stillbirth.

\section{Outcome measures}

Our primary outcome was risk of spontaneous preterm birth $<37$ weeks of gestation per parity. Other outcome variables were spontaneous preterm birth $<32$ and $<28$ weeks. We performed additional analyses for the outcome late spontaneous preterm birth between 34 and 37 weeks to assess pregnancies in women that were not offered additional screening or treatment to prevent recurrent preterm birth. The PERINED registry contains data on whether a delivery started spontaneous (i.e., with spontaneous rupture of the membranes or contractions) or iatrogenic (i.e., planned Caesarean section or induction of labor).

\section{Statistical analysis}

To estimate the effect of parity on spontaneous preterm birth $<37,<32$ and $<28$ weeks (and between 34 and 37 weeks), we used a univariate logistic regression model and expressed the effect estimates as odds ratios (OR) and corresponding 95\% confidence intervals (CI). We used multivariate logistic regression analysis to adjust for the most common known risk factors for preterm birth that were available in the national perinatal registry that we used for our study. The chosen variables were based on previous studies about risk factors for (spontaneous) preterm birth $[6,15,16]$. First, we adjusted for possible maternal confounders (correction model A) including maternal age $(<20$ years, $\geq 40$ years and continuous), non-White ethnicity, low socioeconomic status (SES), and, in multiparous women, a prior preterm birth. Additional analysis were performed to adjust for potentially mediating factors occurring in the pathway between the independent (parity) and dependent (spontaneous preterm birth) variables (correction model B). Correction model B included the maternal confounders as in model $\mathrm{A}$ and in addition artificial reproductive techniques (ART), male fetal gender, hypertension, preeclampsia and small for gestational age $(\mathrm{SGA})<\mathrm{p} 10$. All variables were extracted from PERINED, including SES which was based on the 4 digit postal code of the woman's home address. SES was divided into low $(<$ $25 \%)$, middle (25-75\%) and high (>75\%) status.

In multiparous women (P1 through P4), we used the Cochran-Armitage Trend Test to test for a trend in parity on the incidence of spontaneous preterm birth $<37$, $<32$ and $<28$ weeks (and between 34 and 37 weeks). The data were analyzed with the SAS statistical software package (version 9.3; SAS Institute Inc., Cary, NC).

\section{Results}

We identified 837,226 singleton pregnancies of women who delivered $\geq 22$ weeks of gestation from 2010 through 2014. We excluded pregnancies complicated by stillbirth (3118, [0.37\%]) or congenital abnormalities $(25,444$, 
[3.04\%]). The total of first, second, third, fourth and fifth pregnancies (P0 through $\mathrm{P} 4$ ) with complete follow-up data was 802,119 , of which 30,237 (3.8\%) were spontaneous preterm births $<37$ weeks of gestation. The proportion of pregnancies per parity was $45.8 \%(n=367,676)$ in P0, 36.1\% $(n=289,391)$ in P1, 13.1\% $(n=105,014)$ in P2, $3.8 \%(n=30,585)$ in P3 and $1.2 \%(n=9453)$ in P4 (Table 1).

\section{Maternal and pregnancy characteristics per parity}

The proportion of pregnancies per parity plus the maternal and pregnancy characteristics of the parity groups are presented in Table 1 . The mean maternal age increased with higher parity from 29.25 years in P0 to 35.03 years in P4 $(p<.0001)$. The percentage of nonwhite ethnicity increased with higher parity, $17.3 \%$ nonWhite in P0 compared to $39.8 \%$ in P4 ( $<$.0001). Also the percentage of women with a low SES increased with higher parity, $24.9 \%$ low-SES in P0 increasing to $34.0 \%$ in P4 $(\mathrm{p}<.0001)$. Hypertension and preeclampsia occurred more often in nulliparous women while these rates remained relatively stable in multiparous women (Table 1).

\section{Preterm birth incidence by parity}

The overall incidence of preterm birth $<37$ weeks of gestation among singletons without congenital anomalies was $5.4 \%$ in The Netherlands during the 5 year study period. Rates of spontaneous and iatrogenic preterm birth $<37$ weeks of gestation were 3.8 and $1.7 \%$, respectively (Table
1). The incidence of total, spontaneous and iatrogenic preterm birth stratified for parity are presented in Fig. 1 and Table 1. The highest incidence of spontaneous preterm birth was observed among nulliparous women (P0, 4.9\%) and women in their fifth pregnancy (P4, 3.7\%) (Fig. 1 and Table 1). In addition, among the 18,170 women in their second, third, fourth or fifth pregnancy who had a preterm birth, $8 \%$ ( $n=1446$ out of 18,170 women) had a prior preterm birth and $92 \%$ were new preterm births (Table 1 ). These percentages per parity were $8.0 \%$ for $\mathrm{P} 1,7.9 \%$ for P2, 8.1\% for P3 and 7.2\% for P4 (Table 1).

\section{Parity and risk of spontaneous preterm birth by gestational age}

Spontaneous preterm birth risks by gestational age were examined for parity. We used women in their second pregnancy (P1) as reference; the results are demonstrated in Table 2 and Fig. 2.

Both nulliparous women and women in their fifth pregnancy had the highest risk for all preterm birth outcomes. Preterm birth risk in nulliparous women slightly increased after adjusting for confounders compared to the unadjusted risk, whereas in women in their fifth pregnancy the risk slightly decreased after correcting for the same confounders (Table 2 and Fig. 2).

For spontaneous preterm birth $<37$ weeks we observed the highest risk in nulliparous women (OR 1.95, 95\% CI $1.89-2.00)$ and women in their fifth pregnancy (OR 1.26, 95 CI 1.13-1.41) (Fig. 2a). For spontaneous preterm birth $<32$ weeks, nulliparous women had the highest risk (OR

Table 1 Comparison of maternal and pregnancy characteristics and outcomes between the different parity groups

\begin{tabular}{|c|c|c|c|c|c|c|c|}
\hline & Total & PO & P1 & $P 2$ & P3 & P4 & $P$-value* \\
\hline Number of subjects (\%) & $802,119(100)$ & $367,676(45.8)$ & $289,391(36.1)$ & $105,014(13.1)$ & $30,585(3.8)$ & $9453(1.2)$ & NA \\
\hline Mean GA in weeks (SD) & $39.1(1.8)$ & $39.08(2.0)$ & 39.18 (1.6) & $39.15(1.7)$ & $39.03(1.8)$ & $38.94(2.0)$ & NA \\
\hline Mean maternal age (SD) & $30.8(4.8)$ & $29.25(4.9)$ & $31.53(4.4)$ & $32.98(4.3)$ & $34.03(4.4)$ & $35.03(4.5)$ & $<.0001$ \\
\hline Maternal age < 20 yrs (\%) & $10,201(1.3)$ & $9230(2.5)$ & $902(0.3)$ & $61(0.1)$ & $7(0.02)$ & $1(0.01)$ & $<.0001$ \\
\hline Maternal age $\geq 40$ yrs (\%) & $24,797(3.1)$ & $6891(1.9)$ & 8505 (2.9) & $5310(5.1)$ & $2785(9.1)$ & $1306(13.8)$ & $<.0001$ \\
\hline Non-White (\%) & $152,899(19.1)$ & 63,754 (17.3) & 49,303 (17.0) & $25,427(24.2)$ & $10,650(34.8)$ & 3765 (39.8) & $<.0001$ \\
\hline LOW SES (\%) & $197,136(24.6)$ & $91,433(24.9)$ & $65,885(22.8)$ & $27,006(25.7)$ & $9602(31.4)$ & $3210(34.0)$ & $<.0001$ \\
\hline Prior PTB (\%) & $6858(0.9)$ & 0 & $4208(1.5)$ & $1825(1.7)$ & $623(2.0)$ & $202(2.1)$ & $<.0001$ \\
\hline ART (\%) & $29,763(3.7)$ & $19,838(5.4)$ & $8148(2.8)$ & $1436(1.4)$ & $276(0.9)$ & $65(0.7)$ & $<.0001$ \\
\hline Male fetal gender (\%) & $409,097(51.0)$ & $187,681(51.1)$ & $147,586(51.0)$ & $53,361(50.8)$ & $15,588(51.0)$ & $4881(51.63)$ & 0.6184 \\
\hline Hypertension and preeclampsia (\%) & $70,745(8.8)$ & $43,656(11.9)$ & $18,610(6.4)$ & $5972(5.7)$ & $1869(6.1)$ & $638(6.8)$ & $<.0001$ \\
\hline SGA < p10 (\%) & $67,744(8.5)$ & $30,252(8.2)$ & $25,431(8.8)$ & $8493(8.1)$ & $2724(8.9)$ & $844(8.9)$ & 0.0002 \\
\hline Total PTB & $43,653(5.4)$ & $25.483(6.9)$ & $11,769(4.1)$ & $4353(4.2)$ & $1491(4.9)$ & $557(5.9)$ & NA \\
\hline Spontaneous PTB & $30,237(3.8)$ & $18,171(4.9)$ & $8065(2.8)$ & $2761(2.6)$ & $893(2.9)$ & $347(3.7)$ & NA \\
\hline latrogenic PTB & $13,416(1.7)$ & $7312(2.0)$ & $3704(1.3)$ & $1592(1.5)$ & $598(2.0)$ & $210(2.2)$ & NA \\
\hline Previous PTB in women with PTB & $1446(8.0)$ & NA & $942(8.0)$ & $343(7.9)$ & $121(8.1)$ & $40(7.2)$ & NA \\
\hline
\end{tabular}

Abbreviations: GA gestational age; SD standard deviation; yrs years; SES socio-economic status; PTB preterm birth; $A R T$ artificial reproductive techniques; SGA small for gestational age 


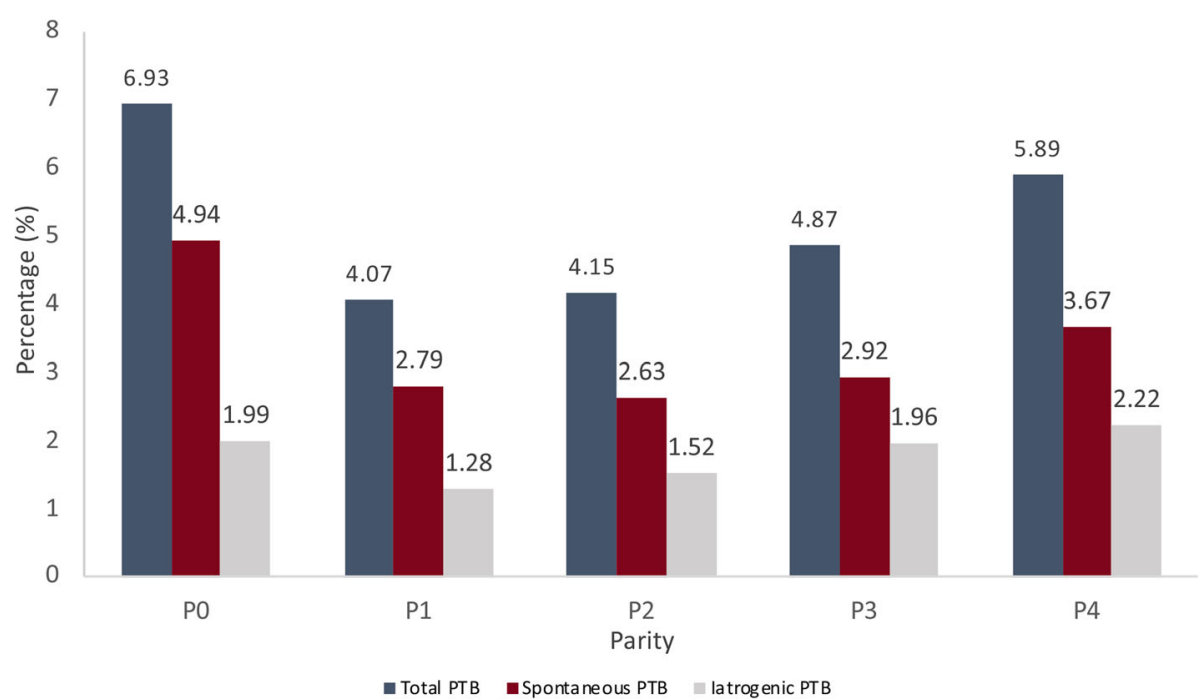

Fig. 1 Incidence rates of overall preterm birth and stratified for spontaneous and iatrogenic preterm birth for women in their first (P0), second (P1), third (P2), fourth (P3) and fifth (P4) pregnancy from 2010 through 2014 in The Netherlands. Abbreviations: PTB, preterm birth

Table 2 Relation between parity and spontaneous preterm birth $<37,<32,<28$ and between 34 and 37 weeks of gestation

\begin{tabular}{|c|c|c|c|}
\hline & Unadjusted OR (95\% Cl) & $A^{*}:$ Adjusted OR $(95 \% \mathrm{Cl})$ & $B^{* *}:$ Adjusted OR (95\% Cl) \\
\hline \multicolumn{4}{|c|}{ PTB < 37 weeks } \\
\hline PO & $1.83(1.78-1.88)$ & $1.95(1.89-2.00)$ & $1.93(1.88-1.98)$ \\
\hline P1 (ref) & 1.0 & 1.0 & 1.0 \\
\hline P2 & $0.94(0.90-0.99)$ & $0.92(0.88-0.97)$ & $0.93(0.89-0.97)$ \\
\hline P3 & $1.06(0.99-1.13)$ & $1.00(0.93-1.08)$ & $1.01(0.94-1.08)$ \\
\hline P4 & $1.34(1.20-1.50)$ & $1.26(1.13-1.41)$ & $1.27(1.14-1.42)$ \\
\hline \multicolumn{4}{|c|}{ PTB $<32$ weeks } \\
\hline PO & $2.04(1.89-2.21)$ & $2.15(1.98-2.33)$ & $2.19(2.02-2.38)$ \\
\hline P1 (ref) & 1.0 & 1.0 & 1.0 \\
\hline P2 & $1.10(0.97-1.25)$ & $1.05(0.92-1.19)$ & $1.06(0.93-1.20)$ \\
\hline P3 & $1.32(1.09-1.59)$ & $1.15(0.95-1.40)$ & $1.17(0.97-1.42)$ \\
\hline P4 & $2.05(1.57-2.67)$ & $1.72(1.31-2.25)$ & $1.76(1.34-2.31)$ \\
\hline \multicolumn{4}{|c|}{ PTB $<28$ weeks } \\
\hline P0 & $1.95(1.72-2.20)$ & $2.02(1.78-2.29)$ & $2.11(1.86-2.39)$ \\
\hline P1 (ref) & 1.0 & 1.0 & 1.0 \\
\hline P2 & $1.07(0.89-1.30)$ & $1.00(0.82-1.21)$ & $1.03(0.85-1.25)$ \\
\hline P3 & $1.65(1.27-2.16)$ & $1.38(1.05-1.81)$ & $1.44(1.10-1.88)$ \\
\hline P4 & $3.10(2.21-4.35)$ & $2.44(1.73-3.45)$ & $2.59(1.84-3.66)$ \\
\hline \multicolumn{4}{|c|}{ PTB 34-37 weeks } \\
\hline PO & $1.75(1.70-1.80)$ & $1.85(1.79-1.91)$ & $1.83(1.77-1.89)$ \\
\hline P1 (ref) & 1.0 & 1.0 & 1.0 \\
\hline P2 & $0.91(0.87-0.96)$ & $0.90(0.85-0.94)$ & $0.90(0.85-0.95)$ \\
\hline P3 & $1.00(0.93-1.09)$ & $0.97(0.89-1.05)$ & $0.97(0.90-1.06)$ \\
\hline P4 & $1.22(1.08-1.39)$ & $1.17(1.03-1.33)$ & $1.18(1.03-1.34)$ \\
\hline
\end{tabular}

Abbreviations: $O R$ odds ratio; $C l$ confidence interval; $P T B$ preterm birth

"Correction model A: Adjusted for maternal age ( $<20$ years, $\geq 40$ years and continuous), non-White ethnicity, low socioeconomic status, and a prior preterm birth

*** Correction model B: Adjusted for A and artificial reproductive techniques, male fetal gender, hypertension, preeclampsia, and small for gestational age $<$ p10 


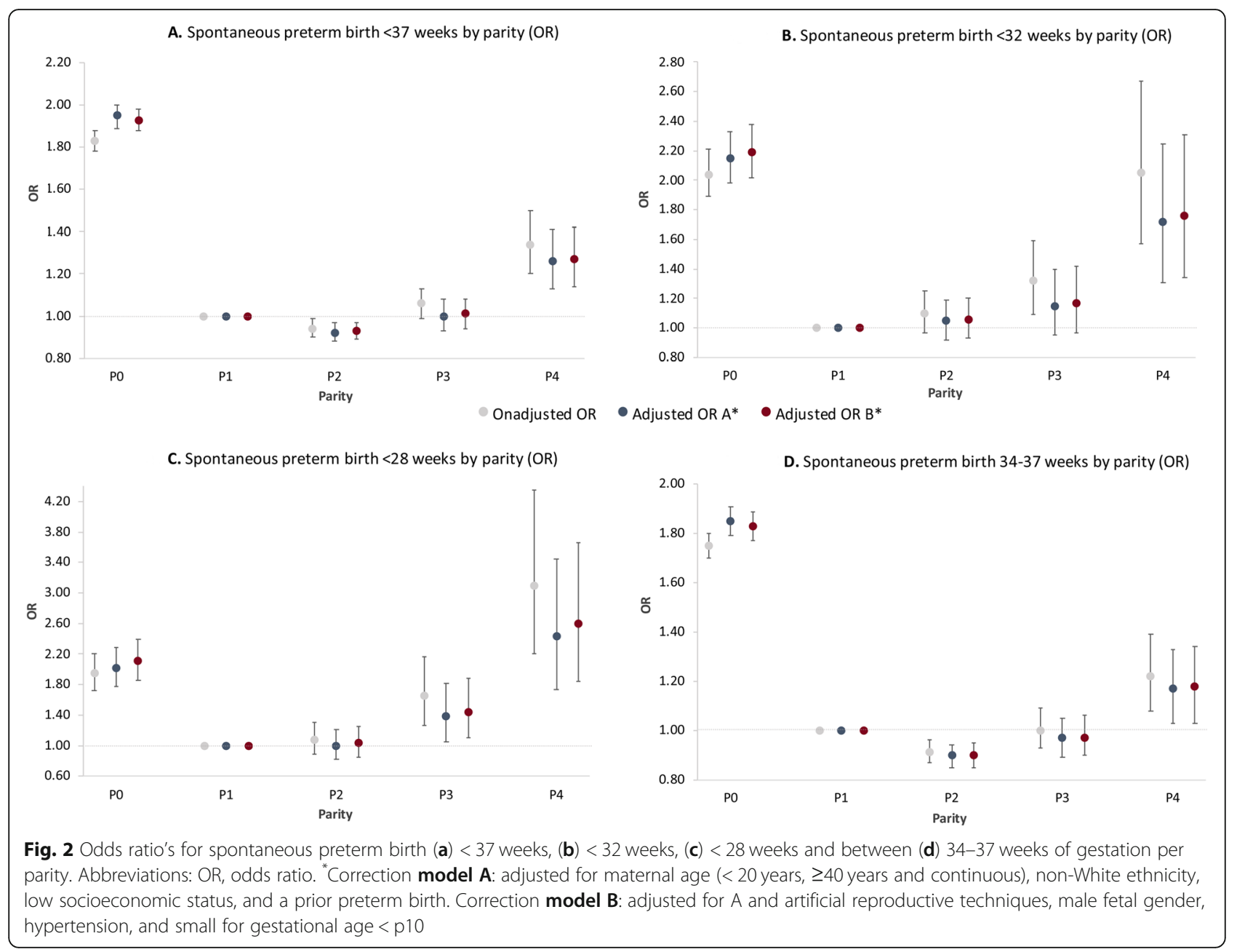

2.15, 95\% CI 1.98-2.3) followed by women in their fifth pregnancy (OR 1.72, 95\% CI 1.31-2.25) (Fig. 2b). Although we observed an increased risk for spontaneous preterm birth $<32$ weeks in women in their fourth pregnancy, no effect was seen after adjusting for confounders (OR 1.15, 95\% CI 0.95-1.40). The risk for spontaneous preterm birth $<28$ weeks was highest in women in their fifth pregnancy (OR 2.44, 95\% CI 1.73-3.45), followed by nulliparous women (OR 2.02, 95\% CI 1.78-2.29) and women in their fourth pregnancy (OR 1.38, 95\% CI 1.051.81) (Fig. 2c). Women in their first pregnancy had the highest risk for a spontaneous preterm birth between 34 and 37 weeks of gestation (OR 1.85, 95\% CI 1.79-2.29) followed by women in their fifth pregnancy (OR 1.17, 95\% CI 1.03-1.33) (Fig. 2d). We did not observe significant differences between results obtained from model $\mathbf{A}$ and model B in all parity groups and outcomes (Table 2).

\section{Trend in incidence of spontaneous preterm birth in multiparous women}

After exclusion of nulliparous women, we observed an increase in incidence of spontaneous preterm birth $<37$ weeks $(p=0.0178),<32$ weeks $(p<.0001)$ and $<28$ weeks $(\mathrm{p}<.0001)$, with increasing parity in multiparous women (Table 3). This trend was in line with our observation of increasing odds ratio's in multiparous women for all three outcomes. No trend was seen in spontaneous preterm birth between 34 and 37 weeks (Table 3).

\section{Discussion}

In this nationwide retrospective study we found that nulliparity (P0) was independently associated with an overall increased risk for spontaneous preterm birth compared to women in their second pregnancy (P1). We also observed an increase in incidence of spontaneous preterm birth $<37,<32$ and $<28$ weeks with higher parity in multiparous women, with highest risk for spontaneous preterm birth $<28$ weeks in women in their fifth pregnancy.

The association between nulliparity and spontaneous preterm birth is supported by other studies [17, 18]. Our study also finds an association between high parity and spontaneous preterm birth. Previous studies mostly assessed the effect of (high) parity in the context of 
Table 3 Trend test in spontaneous preterm birth incidence rates in multiparous women

\begin{tabular}{clllll}
\hline & $P 1$ & $P 2$ & $P 3$ & $P 4$ & $P$-value* \\
\hline $\begin{array}{c}\text { Spontaneous PTB } \\
<37 \text { weeks }\end{array}$ & $8065(2.8 \%)$ & $2761(2.6 \%)$ & $893(2.9 \%)$ & $347(3.7 \%)$ & 0.0178 \\
$<32$ weeks & $873(0.3 \%)$ & $349(0.3 \%)$ & $121(0.4 \%)$ & $58(0.6 \%)$ & $<.0001$ \\
$<28$ weeks & $367(0.1 \%)$ & $142(0.1 \%)$ & $64(0.2 \%)$ & $37(0.4 \%)$ & $251(2.7 \%)$ \\
$34-37$ weeks & $6406(2.2 \%)$ & $21182.0 \%)$ & $675(2.2 \%)$ & NS \\
\hline
\end{tabular}

advanced maternal age [19] or state that the effect of parity is influenced by socioeconomic and health care conditions [11]. More studies have been conducted to assess the association between parity and adverse pregnancy outcomes, however, these studies do not assess preterm birth as a primary outcome $[9,10]$.

The conflicting results of the different studies point to the complexity of the association between possible risk factors, including parity, and spontaneous preterm birth. It also highlights the possible influence of factors that contribute to a higher risk of spontaneous preterm birth, such as ethnicity and socio-economic status. However, in the current study we found an association between high parity and spontaneous preterm birth while adjusting for established risk factors such as ethnicity and socio-economic status. This possibly points to other factors that may contribute to a higher risk of spontaneous preterm birth. One of the factors that may play a role could be a damaged cervix. The cervix plays an important role in maintaining pregnancy. It is well known that damage to the cervix, for instance by dilatation and curettage or loop excisions of the cervix for premalignant lesions, contributes to a higher risk of spontaneous preterm birth [20]. The risk of such procedures being performed is higher in women at higher age or parity, which may be an explanation for the association of parity and spontaneous preterm birth we found.

The overall risk for spontaneous preterm birth was significantly increased in nulliparous women compared to women in their second pregnancy, including the risk of birth between 34 and 37 weeks. According to the national prevention of preterm birth protocol in The Netherlands, women with a prior spontaneous preterm birth between 34 and 37 weeks are not offered additional screening or treatment (such as administration of progesterone, pessary or cerclage, and cervical length screening or bacterial vaginosis screening) and receive similar obstetric care as women without a prior preterm birth [21]. Also, it is unlikely that these treatment effects can explain these differences.

Although our results show that nulliparity and high parity is associated with an increased risk for spontaneous preterm birth, we observed remarkable differences between the association with nulliparity compared to high parity. While the risk of spontaneous preterm birth $<37,<32$ and $<28$ weeks in nulliparous women is relatively similar, women in their fourth and women in their fifth pregnancy have a particularly high risk of spontaneous preterm birth occurring at early gestational age (Table 2).

We observed that odds ratios in nulliparous women increased after adjusting for confounders whereas odds ratio's in multiparous women decreased after adjusting. These data point to differences in the effect of established confounders on spontaneous preterm birth between different parity groups. This is in line with the significant differences we observed in the confounders low and high maternal age, non-White ethnicity and low socio-economic status between nulliparous and multiparous women.

\section{Strengths and limitations of this study}

The strengths of this study include the high quality of data in the PERINED registry which covers approximately $97 \%$ of all deliveries in the Netherlands. We were able to study a large recent set of pregnancies $(n=802$, 119 ), including first, second, third, fourth and fifth pregnancies, and 30,237 spontaneous preterm births <37 weeks of gestation.

Multiple epidemiologic studies have reported associations of nulliparous women with increased risk of preterm birth [9, 18, 22-24]. Yet, in many of these studies, parity has been categorized as nulliparous and multiparous, with women with their second pregnancy often grouped in with those of higher-order parity. In our study, we evaluated the effect per parity separately which allowed us to identify the increased risk in both nulliparous women and women with higher parity.

Unfortunately, due to low reporting within the perinatal database, we were not able to correct for smoking during pregnancy and maternal body mass index (BMI) in our analyses. The general incidence of smoking in The Netherlands is $22.4 \%$ in the population $>18$ years old, $19.2 \%$ of all women are smokers [25]. The incidence of smoking in pregnant women in The Netherlands is 
7.4\% [26]. The general incidence of obesity in The Netherlands is $50.2 \%$ in the population $>18$ years, of all women $47.2 \%$ has obesity (30.4\% has moderate obesity and 16.9 has severe obesity) [27]. Smoking and very low or very high maternal BMI are known risk factors for spontaneous preterm birth $[28,29]$. This may have influenced our results. Because we corrected for low socioeconomic status in our analyses, and it is known that low socio-economic status is strongly correlated to both smoking and maternal obesity, we do not think that this issue of missing adjustment factors has influenced our results to a large degree. In addition to smoking and BMI, we were not able to correct for other potential risk factors that contribute to the risk of preterm birth, such as polyhydramnios, intra-uterine infection, single marital status, short interpregnancy interval $(<6$ months $)$ and specific maternal diseases (uterus anomaly, cervical excision procedures, maternal surgery during pregnancy, depression) [6].

Pregnancies ending $<22$ weeks were not included in our national database. Although we corrected for a prior preterm birth, which was available in our dataset, we did not have information on multiple occurrence nor severity of the prior preterm birth. Because no longitudinal linked obstetric database was available, pregnancies could not be related to the level of the individual woman in this study. We therefore could not identify women that were included multiple times due to multiple pregnancies between 2010 and 2014 which may have influenced our results.

\section{Conclusion}

Our findings indicate that high parity, as well as nulliparity, is involved as a risk factor in the complex pathways that lead to spontaneous preterm birth. These results highlight the importance of the effect of parity on spontaneous preterm birth and may assist in preterm birth risk stratification and counseling.

\section{Abbreviations}

ART: Artificial reproductive techniques; GA: Gestational age; OR: Odds ratio; PTB: PRETERM birth; SD: Standard deviation; SES: Socio-economic status; SGA: Small for gestational age

\section{Acknowledgements \\ The authors thank the Dutch midwives, obstetricians, neonatologists, and other perinatal health care providers for the registration of perinatal information and the foundation of the Netherlands Perinatal Registry (www. perined.nl) for permission to use the registry data (approval no. 17.34).}

\section{Authors' contributions}

$B K, A R$ and $M O$ designed the study, BK and AR analyzed the data, BK and MvZ wrote the first draft of the manuscript, BM, MO, BWM, EP and AR critically revised the manuscript, BK and MvZ finalized the manuscript. All authors have read and approved the manuscript.

\section{Funding}

BWM is supported by a NHMRC Practitioner Fellowship (GNT1082548). BWM critically revised the manuscript of this study.

\section{Availability of data and materials}

This study was based on data from the Netherlands Perinatal Registry (PERINED). This database is a population based registry that is not publicly accessible. Approval from PERINED is acquired.

\section{Ethics approval and consent to participate}

The data in the perinatal registry are anonymous; therefore, ethical approval was not mandatory under Dutch law. The Netherlands Perinatal Registry gave their approval for the use of their data for this study (approval no. 17.34).

\section{Consent for publication}

Not applicable.

\section{Competing interests}

BWM reports consultancy for ObsEva, Merck and Guerbet. There are no other disclosures to report for other authors.

\section{Author details}

${ }^{1}$ Department of Obstetrics and Gynecology, Amsterdam UMC, University of Amsterdam, Meibergdreef 9, 1105, AZ, Amsterdam, The Netherlands. ${ }^{2}$ Department of Obstetrics and Gynecology, School of Medicine, Monash University, Melbourne, Australia. ${ }^{3}$ Department of Medical Informatics, Amsterdam UMC, University of Amsterdam, Meibergdreef 9, Amsterdam, The Netherlands.

Received: 31 December 2019 Accepted: 13 April 2020

Published online: 21 April 2020

\section{References}

1. Ananth CV, Vintzileos AM, Vintzileos AM. Epidemiology of preterm birth and its clinical subtypes. J Matern Fetal Neonatal Med. 2006;19(12):773-82.

2. Wen SW, Smith G, Yang Q, Walker M. Epidemiology of preterm birth and neonatal outcome. Semin Fetal Neonatal Med. 2004;9(6):429-35.

3. Saigal S, Doyle LW. An overview of mortality and sequelae of preterm birth from infancy to adulthood. Lancet (London, England). 2008;371(9608):261-9.

4. Blencowe H, Cousens S, Chou D, Oestergaard M, Say L, Moller A-B, et al. Born too soon: the global epidemiology of 15 million preterm births. Reprod Health. 2013;10(Suppl 1):S2.

5. Romero R, Espinoza J, Kusanovic JP, Gotsch F, Hassan S, Erez O, et al. The preterm parturition syndrome. BJOG. 2006;113(Suppl):17-42.

6. Goldenberg RL, Culhane JF, lams JD, Romero R. Epidemiology and causes of preterm birth. Lancet. 2008;371(9606):75-84.

7. Esplin MS, O'Brien E, Fraser A, Kerber RA, Clark E, Simonsen SE, et al. Estimating recurrence of spontaneous preterm delivery. Obstet Gynecol. 2008;112(3):516-23.

8. Auger N, Hansen AV, Mortensen L. Contribution of maternal age to preterm birth rates in Denmark and Quebec, 1981-2008. Am J Public Health. 2013. 103(10):e33-8.

9. Bai J, Wong FWS, Bauman A, Mohsin M. Parity and pregnancy outcomes. Am J Obstet Gynecol. 2002;186(2):274-8.

10. Jacquemyn $Y$, Senten $L$, Vellinga $S$, Vermeulen $K$, Martens $G$. Does practice make perfect? An age-matched study on grand multiparity in Flanders. Belgium J Perinat Med. 2006;34(1):28-31.

11. Babinszki A, Kerenyi T, Torok O, Grazi V, Lapinski RH, Berkowitz RL. Perinatal outcome in grand and great-grand multiparity: effects of parity on obstetric risk factors. Am J Obstet Gynecol. 1999 Sep 1;181(3):669-74.

12. Shah PS. Parity and low birth weight and preterm birth: a systematic review and meta-analyses. Acta Obstet Gynecol Scand. 2010;89(7):862-75.

13. Méray N, Reitsma JB, Ravelli ACJ, Bonsel GJ. Probabilistic record linkage is a valid and transparent tool to combine databases without a patient identification number. J Clin Epidemiol. 2007;60(9):883-91.

14. Tromp M, Ravelli ACJ, Méray N, Reitsma JB, Bonsel GJ. An efficient validation method of probabilistic record linkage including readmissions and twins. Methods Inf Med. 2008;47(4):356-63.

15. Koullali B, Oudijk MA, Nijman TAJ, Mol BWJ, Pajkrt E. Risk assessment and management to prevent preterm birth. Semin Fetal Neonatal Med. 2016;21: 2.

16. Schaaf JM, Ravelli ACJ, Mol BWJ, Abu-Hanna A. Development of a prognostic model for predicting spontaneous singleton preterm birth. Eur J Obstet Gynecol Reprod Biol. 2012;164(2):150-5. 
17. Ananth CV, Peltier MR, Getahun D, Kirby RS, Vintzileos AM. Primiparity: an "intermediate" risk group for spontaneous and medically indicated preterm birth. J Matern Fetal Neonatal Med. 2007;20(8):605-11.

18. Berkowitz GS, Blackmore-Prince C, Lapinski RH, Savitz DA. Risk factors for preterm birth subtypes. Epidemiology. 1998;9(3):279-85.

19. Waldenström U, Cnattingius S, Vixner L, Norman M. Advanced maternal age increases the risk of very preterm birth, irrespective of parity: a populationbased register study. BJOG An Int J Obstet Gynaecol. 2017;124(8):1235-44.

20. Lemmers M, Verschoor MAC, Hooker AB, Opmeer BC, Limpens J, Huirne JAF, et al. Dilatation and curettage increases the risk of subsequent preterm birth: a systematic review and meta-analysis. Hum Reprod. 2016;31(1):34-45.

21. Guideline: Prevention of recurrent spontaneous preterm birth. Dutch Soc Obs Gynaecol. 2007;(v 1.0)

22. Aina-Mumuney AJ, Rai KK, Taylor MY, Weitz CM, Chisholm CA. Nulliparity and duration of pregnancy in multiple gestation. Obstet Gynecol. 2004; 104(1):110-3.

23. Mercer BM, Goldenberg RL, Moawad AH, Meis PJ, lams JD, Das AF, et al. The preterm prediction study: effect of gestational age and cause of preterm birth on subsequent obstetric outcome. National Institute of Child Health and Human Development maternal-fetal medicine units network. Am J Obstet Gynecol. 1999;181(5 Pt 1):1216-21.

24. Simonsen SME, Lyon JL, Alder SC, Varner MW. Effect of grand multiparity on intrapartum and newborn complications in young women. Obstet Gynecol. 2005;106(3):454-60.

25. The incidence of smoking in the general population in The Netherlands [Internet]. Available from: https://www.staatvenz.n//kernciifers/roken.

26. The incidence of smoking in pregnant women in The Netherlands [Internet]. Available from: https://www.staatvenz.nl/kerncijfers/rokenvrouwen-tijdens-zwangerschap.

27. The incidence of obesity in the general population in The Netherlands [Internet]. Available from: https:/www.staatvenz.nl/kernciffers/overgewicht.

28. McCowan LME, Dekker GA, Chan E, Stewart A, Chappell LC, Hunter M, et al. Spontaneous preterm birth and small for gestational age infants in women who stop smoking early in pregnancy: prospective cohort study. BMJ. 2009; 338:b1081.

29. Cnattingius S, Villamor E, Johansson S, Bonamy A-KE, Persson M, Wikström A-K, et al. Maternal obesity and risk of preterm delivery. JAMA. 2013;309(22): 2362

\section{Publisher's Note}

Springer Nature remains neutral with regard to jurisdictional claims in published maps and institutional affiliations.

Ready to submit your research? Choose BMC and benefit from:

- fast, convenient online submission

- thorough peer review by experienced researchers in your field

- rapid publication on acceptance

- support for research data, including large and complex data types

- gold Open Access which fosters wider collaboration and increased citations

- maximum visibility for your research: over $100 \mathrm{M}$ website views per year

At $\mathrm{BMC}$, research is always in progress.

Learn more biomedcentral.com/submissions 